\author{
Military Technical College \\ Kobry El-Kobbah, \\ Cairo, Egypt
}

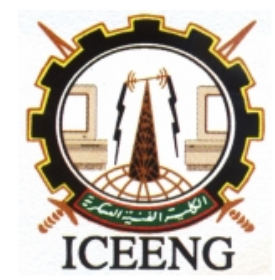

\author{
$8^{\text {th }}$ International Conference \\ on Electrical Engineering \\ ICEENG 2012
}

\title{
Power cables inspection using Matlab graphical user interface aided by thermal camera
}

\author{
By \\ F. fereig Selim* \\ A.Azmy ** \\ I. Bedir***,H. El desuoki ****
}

\section{$\underline{\text { Abstract: }}$}

This paper proposes an efficient method to predict and solve abnormal conditions in all types of electrical cables using Matlab Graphic User Interface "GUI" with thermal imaging infrared "IR" camera. Traditional techniques can not easily predict faults and cannot give a complete diagnose about them. Using any type of thermal cameras enables detecting abnormal conditions of cables by the technical operator (thermographer) depending on their thermal state. Then, thermal images can be sent to the advanced program (GUI) according to the proposed technique. Based on cables database, the proposed interface program and the projected technique are able to: 1) obtain the thermal profile of the system; 2) process and analyze collected thermal data, and 3) apply a simulated artificial technique to define the particular condition or fault corresponding to the thermal signature. The final performed report can contain: 1) problems that are found in the components and the system itself, 2) suggest remedy and any necessary corrective action with time schedule, and 3) give the priority of solving these problems with respect to repair maintenance time, 4) proper selections of cables types and size.

\section{Keywords:}

Matlab Graphic User Interface, thermal imaging infrared

* Department of Electrical Engineering, Kafrelshiekh University, Egypt

** Department of Electrical Engineering, Tanta University, Egypt

*** Department of Electrical Engineering, Taif University, Saudia Arabia

**** Department of Electrical Engineering, Arab Academy for Science and Technology, Egypt

\section{Introduction:}


For long time, faults in electrical equipments and components cause many problems that may lead to severe damages in the equipments and the whole system. Therefore, it is preferable to predict these faults before their actual occurrence to prevent the expected damage. The fault prediction can be achieved by using infrared "IR" cameras, where a thermal signature can be correlated to the operating status of each component [1].

Thermography, or thermal image, is a type of infrared visualization that can be used for this purpose. Thermographic cameras, or shortly thermal cameras, are used in many heavy factories like metal recycling factories, wafer production factories...etc, for monitoring the temperature conditions of machines and electrical elements. When there is any malfunctioning of machines (or other equipments), extra heat will be generated and it can be picked up by thermal camera. Thus, thermal camera can be used to provide images to indicate the condition of machines and equipments. Thermographic inspection of electrical installations is used in three main areas; 1) power generation, 2) power transmission and 3) power distribution, i.e. industrial utilization of electrical energy [23].Recently, thermal imaging is explored in enormous medical and industrial applications. In medical practice, thermal infrared imaging is becoming important since the assessment of pain represents a difficult topic that may be facilitated by the quantification of some of the phenomena usually involved in the sensation of pain, such as thermal abnormalities. Thus, infrared thermal imaging is well thermal, temporal, and spatial resolutions. In addition, infrared cameras can be used as a robust method for analyzing the various speeds of multitudinous vehicles by utilizing thermal images as the source of operation. Comparing thermal images at normal and abnormal conditions would simplify many diagnostic techniques. The use of thermal imaging monitoring is much convenient compared to conventional maintenance methods. With aids of thermal imaging, the operator can maintain and monitor all equipments by just observing their thermal images captured routinely and displayed on a monitor, even from remote locations. So, this can improve safety and reduce hands on workload, man power and maintenance time. Since some overheat devices cannot see through eyes, but can read from thermal images, hence the use of thermal imaging monitoring can prevent accident happen too [4-9]. In fact, infrared imaging and associated temperature measurement, throughout the temperature rise, have a much wider role to play in the field of predictive maintenance throughout the electrical, mechanical, civil, and medical fields. In high voltage applications, the main advantage of IR cameras is the possibility of an inspection far from the equipment, as there is no need for a direct contact. It is also a non-invasive technique to be used with equipments operating under high voltage levels or conducting a high current. In high and low voltage equipments, cables, transmission lines, motors, transformers, circuit breakers, switchgear, sub-stations (typically, a distribution utility will check overhead lines every 2 years, bulk supply substations $(13 / 33 \mathrm{kV})$ every year, and primary substations $(33 / 11 \mathrm{kV})$ every $3 / 4$ years $)$ all can be inspected and pre-failure conditions as well as actual causes can be identified. 
Using IR cameras can save system cost as a result of:

- Increasing safety

- Improving overall productivity

- Reducing downtime and production interruption

- Avoiding damage to equipment property, materials work in process, and overall systems.

- Improving useful life and reducing running costs of motors, drives and bearings

- Avoiding unnecessary and unscheduled maintenance

- Improving energy and production efficiencies

Most of problematic may be result from corrosion, loose connections and phase imbalances. Most of these conditions will result in a distinct temperature rise that can be detected with a portable thermal imaging system. The temperature rise effects are:

i) increase of the resistance of pure metals

ii) increase of the resistance of alloys

iii) decrease of the resistance of electrolytes and partial conductors etc.

The temperature coefficient of resistance finds its importance in determining the behavior of materials that are subjected to temperature changes, in metals the temperature rise leads to an increase of the metals resistance, which leads to decrease of current ampacity. The usage of infrared thermograph in electrical plants and other electrical circuits or components is becoming more widespread and the methodology of its use and practical implementation of predictive maintenance routines are changing [10-13].

\section{Application of Conventional Software}

Whilst the actual inspection and capture of the plant equipment infrared images is an important part of any survey, analysis, categorizing and report writing have historically formed a more problematic challenge for the infrequent thermographer. Historically, infrared cameras were relatively expensive, had short service life/high maintenance and required considerable skill and training for use, image analysis and reporting. The conventional method dependent mainly up on contracting with others (professional inspection company) to do inspections for others. 


\section{Proposed Novel Methodology}

In this study a novel Matlab program is used that contains all the information about the electrical cables from standard references: IEC, BS...etc. [14-15]. In addition, information from experiences of multi sources for normal and abnormal conditions is augmented with the standard data to form databases, which are used in the program. In fact, it is intended to simplify the program to any technical operator who has only the fundamental information about the inspected electrical cables and can also use the IR camera to capture and save thermal image(s).[16]

Typical final report will include:

- Identification of the equipment location

- Specific item or component where the temperature rise was detected

- The temperature rise and its severity rating

- A thermograph of the problem area and a corresponding visual photograph

- The probable causes

- Recommendations that can be used to assist the scheduling and implementation of corrective actions.

\section{A. Program Methodology}

The program for the inspection of cables is simplified as shown in the flowchart shown later. The program studies different cable faults in details. In Figure (1), a MATLAB GUI shows the modules of programs that used to diagnose all cable categories.

Figure (1) introduces the GUI report which divided into three sections:

a. Section one (upper): provides the possibility of defining all types of cables (insulations, conductors, .etc.).

b. Section two (left): where the inputs, outputs can be defined to/from the program respectively and also it offers guidelines to program user.

c. Section three (right): indicates the main report (results), thermal-digital photos, problem, remedy, priority, new cross section if needed, percentage loading and insulation state.

As shown in Figure (1) the cable basic information can be defined by a simple and easy manner and thus, the complete information will be automatically defined in the program and will appear in section two. Finally, the technical operator can complete the information by interring additional data that must be given to the program.

B. Steps of Cables Inspection

The novel Matlab GUI Program used for cable inspection basically depends upon the inputs, which are inserted by thermographer and helping by Table (1). Before describing the program, it is proper to define some symbols that are used in the program to understand its steps as introduced in Table (2).

The GUI program steps are:

1- The program takes the thermal and digital photos of the cables (healthy and 
abnormal) from any IR camera memory.

2- The bad, healthy and ambient temperatures (T, T1, T2) can be obtained from the thermal photo, then the temperature difference can be obtained, $\operatorname{diff}=\mathrm{T} 1-\mathrm{T} 2$.

3- The thermographer measures the actual current in cables in amperes (I) by clamp ammeter.

4- The cable information, conductor type (t), insulations (S), cross section area $(\mathrm{r})$, installation types $(\mathrm{k})$, number of circuits or cores $(\mathrm{x})$... etc. will be chosen according to the selection of cable information (Table (2)).

5- The thermal photos can decide the problem types according to Table (2), and then operator can decide the number of SU (1/ 2 / 3 or 4$)$.

6- After defining the abovementioned information (data), bushing running button will start the processing and the final complete report will appear as will be shown while discussing different cases later. The two columns of input and outputs will disappear when the report is illustrated (left corner).

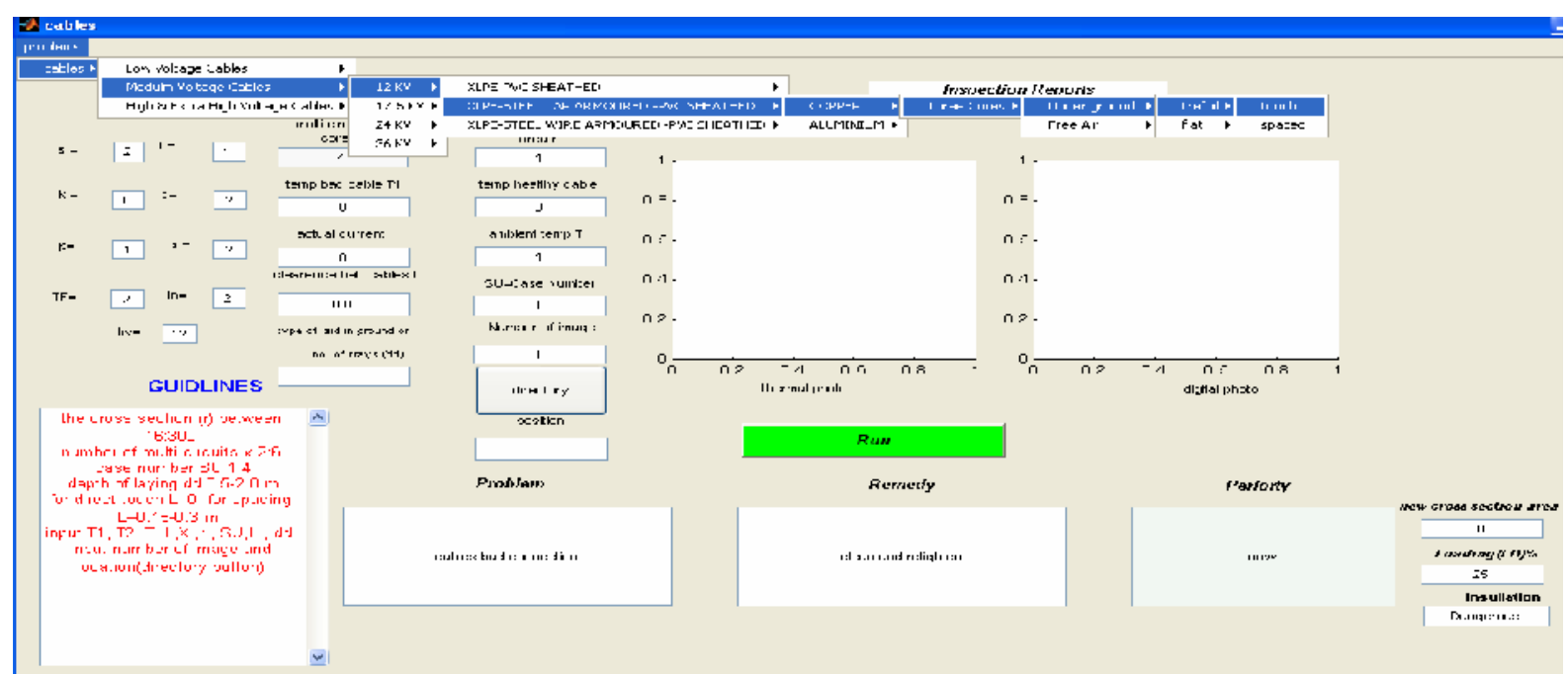

Figure (1): Selection problem and its sequences

\section{Inspection Cables Flowchart}

Figure (2) shows the flowchart (cables cases) of proposed methodology. 


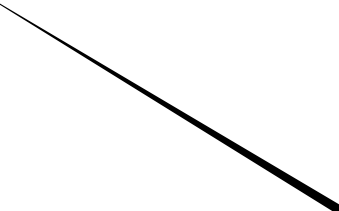

Proceedings of thr $\boldsymbol{s}^{\text {th }}$ ICEENG Conference, 29-31 May, 2012

Input the sten data

$(I, T 1, T 2, T, S u L t, b s, c s, r, p, c c)$

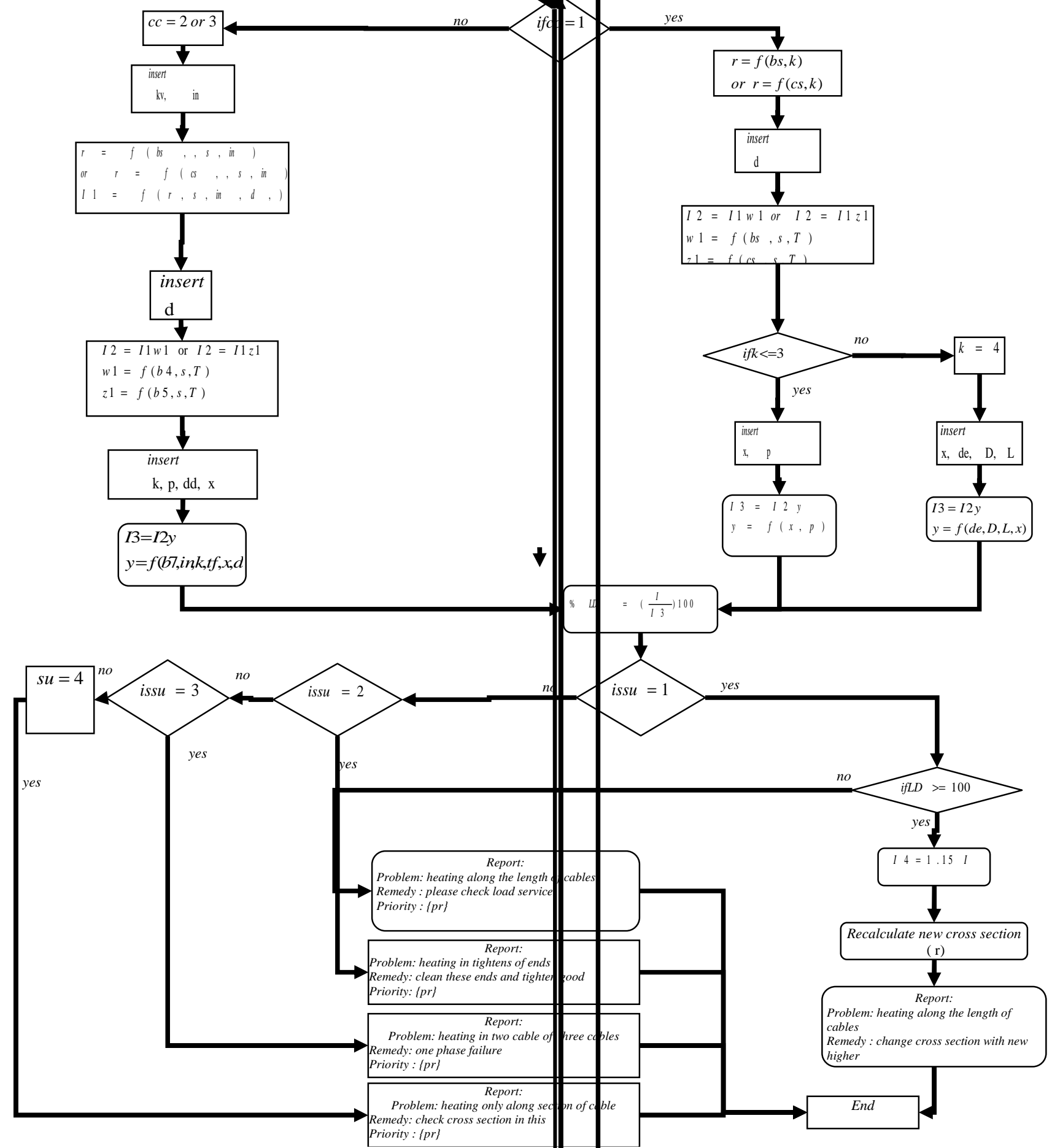

Figure(2): Flow Chart (Cable Cases) of Proposed Matlab Program Methodology 
Table (1): Relationship Between Loading-Temperature Difference and Priority

\begin{tabular}{|c|c|l|}
\hline $\begin{array}{c}\text { Temperature difference } \\
\text { (diff) }\end{array}$ & Loading (LD\%) & \multicolumn{1}{|c|}{ Priority } \\
\hline \multirow{5}{*}{ diff $<=10^{\circ} \mathrm{C}$} & $\mathrm{LD}<=25$ & Now \\
\cline { 2 - 3 } & $25<\mathrm{LD}<=50$ & As quickly as possible \\
\cline { 2 - 3 } & $50<\mathrm{LD}<=75$ & As quickly as possible \\
\cline { 2 - 3 } & $75<\mathrm{LD}<=100$ & As per schedule \\
\cline { 2 - 3 } $10<$ diff $<=20^{\circ} \mathrm{C}$ & $\mathrm{LD}>100$ & Check cross section area \\
\hline \multirow{5}{*}{ diff $>20^{\circ} \mathrm{C}$} & $\mathrm{LD}<=25$ & Now \\
\cline { 2 - 3 } & $25<\mathrm{LD}<=50$ & Now \\
\hline & $50<\mathrm{LD}<=75$ & As quickly as possible \\
\cline { 2 - 3 } & $75<\mathrm{LD}<=100$ & As quickly as possible \\
\cline { 2 - 3 } & $\mathrm{LD}>100$ & Check cross section area \\
\hline & $\mathrm{LD}<=25$ & Now \\
\cline { 2 - 3 } & $25<\mathrm{LD}<=50$ & Now \\
\cline { 2 - 3 } & $50<\mathrm{LD}<=75$ & Now \\
\cline { 2 - 3 } & $75<\mathrm{LD}<=100$ & Now \\
\cline { 2 - 3 } & $\mathrm{LD}>100$ & Check cross section area-Now \\
\hline
\end{tabular}

\section{Cables Case Studies}

The actual cable problems that can be analyzed using thermographic inspection are discussed through the follows case studies:

Case (1): Heating along $20 \mathrm{~cm}$ on One Core, $S U=2$ (Low Voltage)

In this case, one core, the middle one of three-core cable, with two healthy cores is overheated with approximately a rise of $9.1^{\circ} \mathrm{C}$ with respect to others. The cable has an actual current of $50 \mathrm{~A}$ with copper conductors (t) and a cross section area (r) equal to 50 $\mathrm{mm}^{2}$. The dependency on the experiences of technical operator may not give accurate decision to the complete diagnose of the problem. With the proposed GUI program, the technical operator is required to insert only the fundamental information about cable(s) and pushes running button, and the report will be obtained as shown in Figure (3)., Based on the database included in the program, the report will indicate complete information about the problem, solving methods, priority of correction action according to Table (1), etc. The final observations of report related to this case are:

1- the insulation of cable (PVC) has no thermal problem.

2- the cable is loaded by $61.68 \%$ of its ampacity and the temperature difference is $9.1^{\circ} \mathrm{C}$, which give a priority "as quickly as possible", highlighted by yellow 


\section{Table (2): Symbols and Definitions Used in Matlab Program}

\begin{tabular}{|c|c|c|c|}
\hline Symbol & \multicolumn{3}{|c|}{ Definitions } \\
\hline & Low Voltages & \multicolumn{2}{|l|}{ Medium, High and Extra High Voltages $_{2}$} \\
\hline $\mathrm{T} 1$ & Temperature of tested cable(s) & \multicolumn{2}{|l|}{ Temperature of tested cable(s) } \\
\hline $\mathrm{T} 2$ & Temperature of healthy cable(s) & \multicolumn{2}{|l|}{ Temperature of healthy cable(s) } \\
\hline $\mathrm{T}$ & Ambient temperature & \multicolumn{2}{|l|}{ Ambient temperature } \\
\hline diff & Difference between T1 and T2 & \multicolumn{2}{|l|}{ Difference between T1 and T2 } \\
\hline $\mathrm{I}$ & Actual current in bad cable(s) & \multicolumn{2}{|l|}{ Actual current in bad cable(s) } \\
\hline SU(i) & $\begin{array}{l}\text { The type of faults (problems) in cables: } \\
\mathrm{i}=1 \text {, if the heating is along the length of the three cables } \\
\mathrm{i}=2 \text {, if only heating is on tighten along section (not excess } \\
\text { one meter) (three phase or single phase) } \\
\mathrm{i}=3 \text {, if heating is only along two cables out of three cables } \\
\mathrm{i}=4 \text {, if heating is only along section of cable }\end{array}$ & \multicolumn{2}{|c|}{$\begin{array}{l}\text { The type of faults (problems) in cables: } \\
\mathrm{i}=1 \text {, if the heating is along the length of the three cables } \\
\mathrm{i}=2 \text {, if only heating is on tighten along section (not excess } \\
\text { one meter) (three phase or single phase) } \\
\mathrm{i}=3 \text {, if heating is only along single cable of three cables } \\
\mathrm{i}=4 \text {, if heating } \underline{\text { is }} \text { only along section of cable }\end{array}$} \\
\hline $\operatorname{Pr}$ & $\begin{array}{l}\text { Priority of action to repair or maintenances (according to table } \\
\text { II ) }\end{array}$ & \multicolumn{2}{|c|}{$\begin{array}{l}\text { Priority of action to repair or maintenance (according to tables and } \\
\text { problems itself) }\end{array}$} \\
\hline $\mathrm{t}$ & Type of cable conductor ( 1 for copper, 2 for aluminum) & \multicolumn{2}{|c|}{ Type of cable conductor ( 1 for copper, 2 for aluminum) } \\
\hline bs, cs & $\begin{array}{l}\text { Tables of CU and Al current ampacity with cross sections } \\
\text { (according to IEC standards) }\end{array}$ & \multicolumn{2}{|c|}{$\begin{array}{l}\text { Tables of CU and Al current ampacity with cross sections_(according to } \\
\text { El-Sewedy cables) }\end{array}$} \\
\hline \multirow[t]{3}{*}{ S(i) } & \multirow{3}{*}{$\begin{array}{l}\text { The types of cable insulations: } \\
i=1,3 \text { for PVC two and three cores respectively } \\
i=2,4 \text { for XLPE -EPR two and three cores respectively }\end{array}$} & \multicolumn{2}{|c|}{ The types of cable insulations: } \\
\hline & & Medium Voltages & $\begin{array}{l}\text { High and Extra High } \\
\text { Voltages }\end{array}$ \\
\hline & & $\begin{array}{l}\mathrm{i}=1 \text {, for single-multi core XLPE } \\
\text { insulated and PVC sheathed } \\
\mathrm{i}=2 \text {, for multi-core XLPE insulated } \\
\text { steel tape armoured and PVC sheathed } \\
\mathrm{i}=3 \text {, for multi-core XLPE insulated } \\
\text { steel wire armoured and PVC } \\
\text { sheathed }\end{array}$ & $\begin{array}{l}\mathrm{i}=1 \text {, for single core XLPE } \\
\text { insulated sheathed and HDPE } \\
\text { sheathed } \\
\mathrm{i}=2 \text {, for single core XLPE } \\
\text { insulated wire screen and } \\
\text { HDPE sheathed }\end{array}$ \\
\hline $\mathrm{k}(\mathrm{i})$ & $\begin{array}{l}\text { The type of installations: } \\
\mathrm{i}=1 \text { for type A that contains: } \\
\text { 1-one cable with multi cores installed direct in insulation wall } \\
\text { 2-insulation wires in pipe into closed box } \\
\text { 3-cables with multi cores in pipe into insulation wall } \\
\mathrm{i}=2 \text { for type B that contains: } \\
\text { 1-insulation wires in trunk on the wall } \\
\text { 2-insulation wires in pipe into air tunnel } \\
\text { 3-insulation wires with single core or multi cores in pipe or } \\
\text { duct into concrete } \\
\mathrm{i}=3 \text { for type } \mathrm{C} \text { that contains: } \\
\text { 1-cable with single core into wall or floor or ceiling } \\
\text { 2- cable with multi cores into concrete } \\
3 \text { - cable with multi cores on floor into open and air tunnel } \\
\text { 4-cable with multi cores into box or pipe in fresh air or contact } \\
\text { to concrete) } \\
\mathrm{i}=4 \text { for type D that contains:(cable with single core or multi } \\
\text { cores under ground type of cable installation) }\end{array}$ & \multicolumn{2}{|c|}{$\begin{array}{l}\text { The type of installations for: } \\
\text { 1) single core cables in free air (medium only) } \\
i=1 \text {, three cables in horizontal formation perforated trays_(touching) } \\
i=2 \text {, three cables in horizontal formation ladder supports cleats } \\
\text { (touching) } \\
i=3 \text {, three cables in horizontal formation perforated trays(spaced) } \\
i=4 \text {, three cables in trefoil formation vertical perforated trays (spaced) } \\
i=5 \text {, three cables in trefoil formation ladder supports cleats (spaced) } \\
2 \text { ) multi-core cables in free air } \\
i=1 \text {, cables in perforated trays(touching and spaced) } \\
i=2 \text {, cables on vertical perforated trays (touching and spaced) } \\
i=3 \text {, cables ladder supports cleats (touching and spaced) }\end{array}$} \\
\hline $\mathrm{d}$ & installation cable(s) (=1 for air, $=2$ for under-ground) & \multicolumn{2}{|c|}{ installation cable(s) (=1 for air, $=2$ for under-ground $)$} \\
\hline $\mathrm{D}$ & Diameter of cable(s) & \multicolumn{2}{|l|}{ Diameter of cable(s) } \\
\hline $\mathrm{L}$ & Clearance between cables (cores) & \multicolumn{2}{|l|}{ Clearance between cables (cores) } \\
\hline LD & Percentage of cable(s) loading \% & \multicolumn{2}{|l|}{ Percentage of cable(s) loading $\%$} \\
\hline $\mathrm{I} 1, \mathrm{I} 2, \mathrm{I} 3, \mathrm{I} 4$ & $\begin{array}{l}\text { Current from tables current ampacity according to their } \\
\text { equations (calculations) }\end{array}$ & \multicolumn{2}{|c|}{$\begin{array}{l}\text { Current from tables current ampacity according to their equations } \\
\text { (calculations) }\end{array}$} \\
\hline $\mathrm{X}$ & The number of multi circuits or multi cores & \multicolumn{2}{|l|}{ The number of multi circuits or multi cores } \\
\hline $\mathrm{P}$ & $\begin{array}{l}=1 \text { for cables direct touch } \\
=2 \text { for cables indirect touch }\end{array}$ & \multicolumn{2}{|l|}{$\begin{array}{l}=1 \text { for cables direct touch } \\
=2 \text { for cables indirect touch }\end{array}$} \\
\hline $\mathrm{tf}(\mathrm{i})$ & & \multicolumn{2}{|c|}{$\begin{array}{l}\mathrm{i}=0 \text {, direct laid in ground or air } \\
\mathrm{i}=1 \text {, trefoil } \\
\mathrm{i}=2 \text {, flat }\end{array}$} \\
\hline dd(i) & $\begin{array}{l}\text { Type of laid in ground: } \\
\mathrm{i}=1 \text {, depth } 0.7 \text { meter (single or multi cores) } \\
\mathrm{i}=2 \text {, single way duct (multi-core) } \\
\mathrm{i}=3 \text {, single way duct (single core) }\end{array}$ & \multicolumn{2}{|c|}{$\begin{array}{l}\text { Type of laid in ground: } \\
\mathrm{i}=0 \text {, direct laid in ground } \\
\mathrm{i}=\text { select value from } 0.5 \text { meter up to } 2.0 \text { meters. } \\
\text { Number of trays in free air: } \\
\mathrm{i}=1 / 2 / 3 \text { Number of trays }\end{array}$} \\
\hline in(i) & & \multicolumn{2}{|l|}{$\begin{array}{l}\text { Type of cable }(s) \\
i=1 \text {, single core } \\
i=2 \text {, multi-core }\end{array}$} \\
\hline cc(i) & $\mathrm{i}=1$, Low Voltage Ratings & \multicolumn{2}{|c|}{$\mathrm{i}=2,3$ Medium and High Voltages Ratings respectively } \\
\hline $\mathrm{kv}$ & & \multicolumn{2}{|c|}{$\begin{array}{l}12,17.5,24 \text { and } 36 \mathrm{kV} \text { for medium voltage } \\
72.5,145 \text { and } 245 \mathrm{kV} \text { for high and extra voltage }\end{array}$} \\
\hline
\end{tabular}


3- the problem is "bad connection of middle bolt". The remedy is "clean this cable end and retightens it good".

Case (2): Heating along $25 \mathrm{~cm}$ on One Core, $S U=2$ (Medium Voltage)

In this case, one core of three-core cable is overheated with two healthy ones. Approximately, a rise of $15^{\circ} \mathrm{C}$ is observed for one core with respect to the others $\left(25^{\circ}\right.$ $\mathrm{C})$. The cable has an actual current of $100 \mathrm{~A}$ with copper conductors (t) and a cross section area (r) equal to $240 \mathrm{~mm}^{2}$. The final report this time is shown in Figure (4). The final observations of report related to this case are:

1- the insulation of cable (PVC) has no thermal problem.

2- the cable is loaded by $25.78 \%$ of its ampacity and the temperature difference is $15^{\circ} \mathrm{C}$, which give priority "Now" with red color, and there is no need to change the cross section area.

3- the problem is "bad connection of one bolt". The remedy is "clean this cable end and retightens it good".

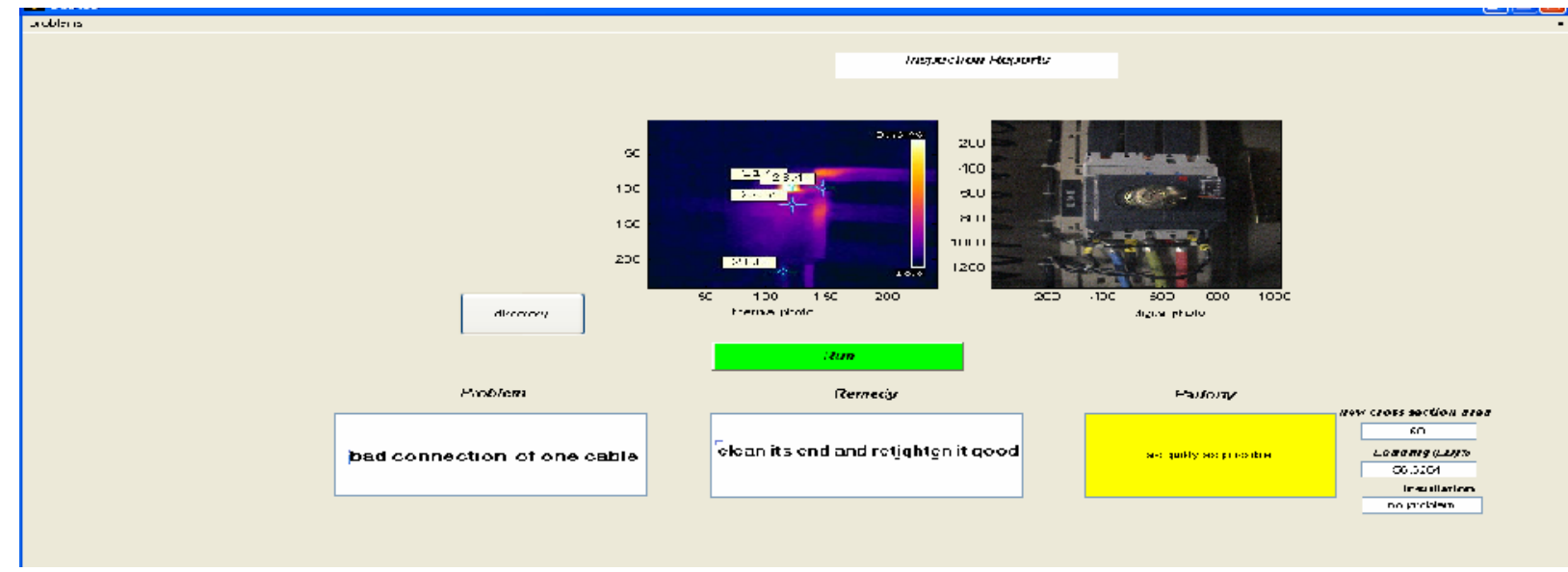

Figure( 3): Report (1), Heating along $20 \mathrm{~cm}$ of one core, $\mathrm{SU}=2$.

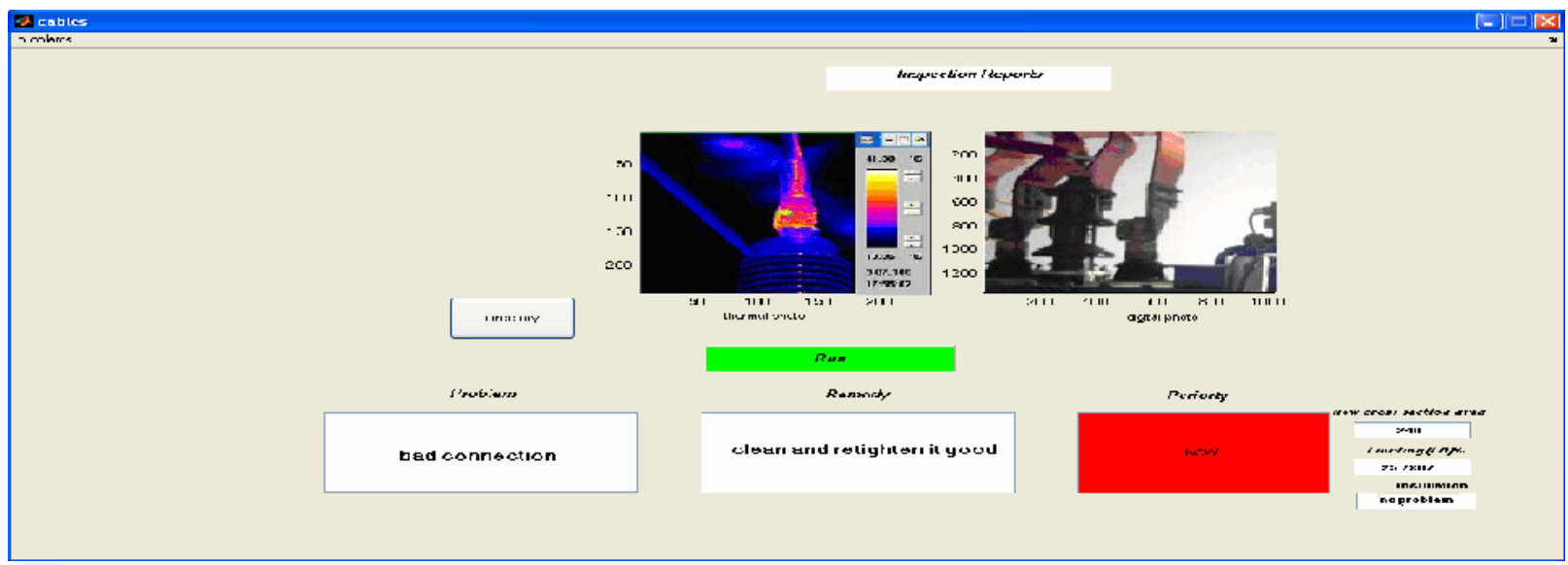

Figure(4): Report (2), Heating along $25 \mathrm{~cm}$ of one core, $\mathrm{SU}=2$.

\section{Discussion And Conclusions}


This paper investigates the use of IR cameras and facilitates its utilization to give optimal solutions of problems associated with electrical elements (equipments) such as cables for different ratings and types. The results obtained with the proposed MATLAB GUI program give the following advantages rather than the traditional techniques that depend on the experience and manual handling:

1- The flexibility of the technique that enables the diagnosis of any electrical equipment. In this case, it is required only to build the databases including all information about the electrical equipment, which can be accomplished in an easy manner.

2- The proposed Matlab GUI program helps saving money by using IR camera for predictive maintenance since professional technicians are not required in inspections).

3- The reliability of the obtained conclusions based on minimizing the user intervention with definite roles and procedures.

4- Time saving due to the short time required to extract the final report about the problem.

5- With simple modifications in the logic structure and database, the program can be applied in different fields including medicine, mechanics, civil...etc. to inspect their problems.

6- The final report can contain the information about the company which having IR camera and its address, thermographer man etc., and the information about location (customer) that inspections taken in, such as address, contact person, etc.

\section{References:}

[1] S. A. M., and R. M. Nelms "Diagnostic Technique for Power Systems Utilizing Infrared Thermal Imaging", IEEE Transaction on Industrial Electronics , Vol.,42,No.6,pp.615-628,December 1995.

[2] W. K W., P. N. Tan, K. L. and S. Lim "Machine condition Monitoring Using Omni directional Thermal Imaging System", IEEE International Conference on Signal and Image Processing Applications,pp.299- 304,2009.

[3] www.flirsystems.com

[4] W.K.W., P.N.Ta., C.K.Loo, and W.S.Lim" An Effective Surveillance Acquisition and Processing (ICSAP), , Kuala Lumpur, Malaysia, pp.13-17, 3-5 Apr 2009.

[5] S. El Sh., M. F., R F. "Thermal Image Prediction by Using An Infrared Thermometer", 13th International Conference on Aerospace Sciences \& Aviation Technology, ASAT- 13Paper: ASAT-13-TH-01,pp.1-8, May 26- 28, 2009. 
[6] R.A., N. N. "Measurement and Analysis of Temperature Rise caused by Handheld Mobile Telephones using Infrared Thermal Imaging", IEEE International RF And Microwave Conference Proceedings, Kuala Lumpur,Malasya,pp.268-273, December 2-4, 2008.

[7] C. L. Heny, M. Frize "Digital Processing Techniques For The Assessment OF Pain With Infrared Thermal Imaging", Proceedings of the Second Joint EMBS/BMES Conference Houston, TX, USA,pp.1157-1158, October 23- 26,2002.

[8] J. R. " Representation of Thermal Infrared Imaging Data in the DICOM Using XML Configuration Files", Proceedings of the 29th Annual International Conference of the IEEE EMBS Cite International, Lyon, France August 2326,pp.258-262, 2007.

[9] A. S., K. Ch. "Robust Method For Analyzing The Various Speeds Of Multitudinous Vehicles In Nighttime Traffic Based on Thermal Images", Fourth International Conference on Computer Sciences and Convergence Information Technology,pp.467-472,2009.

[10] B.S N. " Material Science and Processes" $2^{\text {nd }}$ edition Revised and England,pp.58-59, 1993.

[11] R. S. "Thermal Imaging and Predictive Maintenance: What the Future has in Store" IEEE/PCA $42^{\text {nd }}$ Cement Industry Technical Conference, Salt Lake City, Utah,pp.277-287, May 2000.

[12] E. T. W.N., E. G., and M. J. A. M. "Influence of Emissivity and Distance in High Voltage Equipments Thermal Imaging", 1-4244-0288-/06/\$20.00, 2006 IEEE,pp.1-4,2006.

[13] P J M., F H. "Low Cost Thermal Imaging For Power Systems Applications Using A Conventional CCD Camera", IEEE Catalogue No: 98EX137,pp.589594,1998 .

[14] http://www. IEC .com.

[15] http://www.elsewedy.com

[16] F. Selim, I. Bedir, H. El desuoki "Power Cable Inspections Using Matlab Graphical User Interface Aided by Thermal Imaging " $5^{\text {th }}$ Malaysian Conference in Software Engineering (MySEC), decmber 2011,pp.263-268. 